worsening airway obstruction in a sick toxic child, which can rapidly lead to death by asphyxia unless intervention is prompt. Adult cases, however, can be more challenging to diagnose. Adults may not be toxic, and present with varying degrees of airway obstruction. Viral infections are the commonest cause. Bacterial infection with $H$ influenzae type $\mathrm{b}$, Str pneumoniae, and Staph aureus, although common in children, are rare in adults. Other causes include anaphylaxis, a sudden bleed into a laryngeal tumour, foreign bodies, blunt trauma, smoke inhalation, and caustic ingestion.

Documented clinical outcome of adult supraglottitis varies from benign to life threatening. One prospective study concludes that non- $H$ influenzae aetiologies of adult supraglottitis follow a less pernicious course ${ }^{2}$; this is inconsistent with our experience.

When supraglottitis is suspected, prompt action saves lives. ${ }^{3}$ The diagnosis must therefore be considered in all patients presenting with a sudden onset sore throat and painful dysphagia out of proportion to the extent of oropharyngeal swelling. Stridor is an uncommon initial presentation and the patient may not be toxic.

Regardless of aetiology, the initial management of all suspected cases is similar. Patients require prompt assessment. Heliox, a mixture of helium and oxygen, can temporarily help to maximise the patient's respiratory efforts while help is being summoned, by reducing airflow resistance. Radiography and laboratory investigations are poor predictors of outcome. No attempt to visualise the upper airway should be made until experienced senior anaesthetic and surgical staff are present. There should be a low threshold for definitively securing the airway. A spontaneously breathing induction with halothane offers the safest mode of anaesthesia; sedation and muscular paralysis in these patients may precipitate complete upper airway obstruction. If orotracheal intubation proves difficult or fails, needle (followed by surgical) cricothyroidotomy should be performed without delay. Adrenaline nebulisers have not been proven to be beneficial. ${ }^{4}$ Steroids are in widespread use to reduce supraglottic oedema, despite the risk of immunosuppression.

This case clearly shows how rapidly severe upper airway obstruction can occurorotracheal intubation was required within four hours of the onset of symptoms. In other patients the course may not be so fulminant. Because of this uncertainty, we feel it is essential that all patients with suspected supraglottitis are monitored in a high dependency area. There should be full facilities to secure the airway definitively if necessary. Once ventilated, these patients must be frequently reassessed by indirect laryngoscopy and extubation must not be attempted until the supraglottic oedema has resolved.

We would like to thank Drs Philip Hormbrey and Rebecca Black for their helpful comments in the preparation of this report.

1 Murrage KJ, Janzen VD, Ruby RR. Epiglottitis: adult and paediatric comparisons. J Otolaryngol 1988;17:194-8.

2 Shapiro J, Eavey RD, Baker AS. Adult supraglottitis. A proShapiro J, Eavey RD, Baker AS. Adult suprag
spective analysis. JAMA 1988;259:563-7.

3 Stuart MJ, Hodgetts TJ. Adult epiglottitis: prompt diagnosi saves lives. BMJ 1994;308:329-30.

4 Rivron RP, Murray JAM. Adult epiglottitis: is there consensus on diagnosis and treatment? Clin Otolaryngo $1991 ; 16: 338-44$

\title{
Breaking the rules! Cardiac injury from remote entry sites
}

\author{
V Pathi, F W H Sutherland, A Ireland, K G Davidson
}

\section{Royal Infirmary, \\ Alexandra Parade, \\ Glasgow, UK: \\ Department of \\ Cardiothoracic \\ Surgery \\ V Pathi \\ F W H Sutherland \\ K G Davidson \\ Accident and \\ Emergency \\ Department \\ A Ireland}

Correspondence to: Mr V Pathi, Department of Thoracic Surgery, Hairmyres Hospital, East Kilbride G75 8RG, UK.

Accepted for publication 22 October 1997

\begin{abstract}
An unusual case of penetrating injury to the heart is reported. This presented late, after an initial silent period. A high index of suspicion must be maintained when chest injuries are managed conservatively. If there is doubt, a subxiphoid pericardial window may allow cardiac injury to be excluded.
\end{abstract}

(F Accid Emerg Med 1998;15:115-116)

Keywords: penetrating injury; heart

The epidemic of urban violence has made thoracic stab injuries a common part of surgical practice in the United Kingdom, with well established guidelines for management. ${ }^{1}$ Cardiac injury is particularly likely to occur when the area between the two midclavicular lines has been breached.

We present a case that fell outside traditional guidelines for serious cardiac injury and provides useful lessons for all surgeons.

\section{Case report}

A 25 year old male was stabbed with a kitchen knife, in the left midaxillary line over the sixth intercostal space. He was haemodynamically, radiologically, and electrocardiographically normal when seen five hours later. The next morning, radiography revealed fluid at the left costophrenic angle, and $400 \mathrm{ml}$ of old blood were drained. Echocardiography failed to show cardiac injury or blood in the pericardium. Three hours later, the patient began to complain of severe, acute breathlessness, relieved by a discharge of $700 \mathrm{ml}$ of blood from 
the intercostal drain. The cardiac surgeons were called at this stage but on their arrival, the patient suffered a cardiorespiratory arrest with obvious clinical signs of tamponade. Through an emergency left anterior thoracotomy the pericardium was opened to relieve gross tamponade. A $1.5 \mathrm{~cm}$ laceration in the left ventricular wall was controlled digitally and repaired with two pledgetted, prolene sutures. The entry site into the heart was adjacent to a flap-like communication between the pleura and pericardium anteriorly. The patient made a complete recovery and was discharged on day 10 .

\section{Comment}

The high incidence of cardiac injury with penetrating wounds of the chest medial to the midclavicular lines is well recognised. ${ }^{2}$ However, $80-90 \%$ of wounds lateral to this can be managed conservatively, and thoracotomy reserved for those bleeding in excess of $20 \%$ of their blood volume. ${ }^{13}$

The apparent normality of the chest radiograph, though the weapon clearly traversed the pleural cavity, is surprising. A flap-type mechanism must have decompressed the pericardial blood into the pleural cavity. The normality of the first radiograph would seem to contradict the frequently cited "six hour rule," which states that "asymptomatic patients with stab wounds of the chest do not have delayed complications if the $x$ rays of the chest taken six hours after the injury are normal." ${ }^{14}$ However, the delay in catastrophic bleeding is not surprising when one considers the self sealing nature of the muscular walls of the left ventricle. The initial injury may only have involved the epicardium, the catastrophic bleeding occurring when this had extended to involve the full thickness of the myocardium. The inability of echocardiography to detect such gross injury may have been due the blood discharging into the pleura before the examination. Furthermore, to recognise the difference in contrast between myocardium and clot by echocardiography requires skill and experience, and generally only junior staff are available during the hours of presentation of these injuries.

In our experience, the only definitive method of excluding intrapericardial blood is by direct examination of this cavity through a limited subxiphoid incision in the operating theatre. ${ }^{5}$ This should be done when there is uncertainty about whether cardiac injury has occurred in a clinically stable patient. A short midline vertical incision is performed from the xiphisternum to the linea alba. This is continued through the linea alba and a finger insinuated under the xiphisternum, which is divided vertically with scissors. A self retaining retractor is inserted under each rectus sheath and a hand held retractor used to elevate the sternum proximally. The pericardium is visualised and opened. If blood or clots are seen, the incision can easily and rapidly be converted into a full median sternotomy. Otherwise the wound can readily be closed.

In conclusion, a high index of suspicion must be maintained when chest injuries are managed conservatively. The lack of early symptoms or signs of cardiac tamponade cannot guarantee the absence of serious cardiac damage. If doubt exists, a subxiphoid pericardial window may allow cardiac injury to be excluded.

1 McManus KG, McGuigan JA. Management of chest injuries. Clin Anesthesiol 1992;6:349-80.

2 Jones EW, Helmsworth J. Penetrating wounds of the heart: thirty years experience. Arch Surg 1968;96:671-82.

3 Oparah SS, Mandal AK. Operative management of penetrating wounds of the chest in civilian practice. J Thorac Cardiovasc Surg 1979;77:162-8.

4 Kerr TM, Sood R, Buckman RF, et al. Prospective trial of the six hour rule in stab wounds of the chest. Surg Gynecol Obstet 1989;169:223-5.

5 Andrade-Alegre R, Mon L. Subxiphoid pericardial window in the diagnosis of penetrating cardiac trauma. Ann Thorac Surg 1994;58:1139-41.
Derriford Hospital, Derriford Road, Plymouth, UK: Directorate of Imaging J D Hunter

C A Roobottom

Directorate of Surgery C Brown

The Hyperbaric

Medical Centre,

DDRC Plymouth, Tamar Science Park, Derriford Rd, Plymouth, UK P J Bryson

Correspondence to: Dr J D Hunter, Directorate of Imaging, Taunton and Somerset Hospital, Musgrove Park, Taunton, Somerset TA1 5DA.

\title{
Conservative management of gastric rupture following scuba diving
}

\author{
J D Hunter, C A Roobottom, P J Bryson, C Brown
}

\begin{abstract}
Gastric rupture is an uncommon surgical problem which normally presents with an acute abdomen and peritonism. An unusual case following underwater ascent and its conservative management is presented.

(F Accid Emerg Med 1998;15:116-117)
\end{abstract}

Keywords: gastric rupture; scuba diving; barotrauma

\section{Case report}

A 35 year old diver was air swallowing underwater because of an upper respiratory tract infection. Following a fairly rapid ascent from a depth of $23 \mathrm{~m}$ he developed upper abdominal pain and distension. Gastric rupture was suspected, and both the chest $x$ ray (fig 1 ) and the abdominal $x$ rays revealed a large amount of free intraperitoneal gas. A water soluble contrast study of the upper gastrointestinal tract showed no evidence of 